\title{
SISTEMA NERVOSO E A CONSCIÊNCIA CORPORAL: UM OLHAR PESSOAL A PARTIR DA METODOLOGIA ANGEL VIANNA
}

Luiza Tostes Ferreira Julio ${ }^{\mathrm{i}}$

\begin{abstract}
Resumo: A consciência do corpo é o centro do trabalho realizado na faculdade de dança Angel Vianna. Uma forma de compreender a consciência corporal é com base nos elementos do sistema nervoso envolvidos no processo de sentir, como neurônios e receptores de sensibilidade. Este relato apresenta detalhes sobre o funcionamento do sentido somestésico ou somatossensorial, assim como suas subdivisões propriocepção, exterocepção e interocepção. Será discutido como estes conceitos estão presentes durante o aprendizado da metodologia Angel Vianna a partir de um olhar pessoal, baseado no período de formação da autora, entre os anos 2016 a 2020. Tradicionalmente aprende-se pouco sobre a dimensão sensível do corpo, principalmente de suas camadas mais profundas. Por isso é importante que se possa reconhecer a presença das sensações corporais: nomeá-las e vivenciá-las por meio de um direcionamento consciente da atenção, contribuindo para uma maior agência das escolhas de movimento, regulando graus de esforço e revelando novas possibilidades de ação.
\end{abstract}

Palavras-chave: Metodologia Angel Vianna; Sistema Nervoso; Consciência Corporal.

\section{NERVOUS SYSTEM AND BODY CONSCIOUSNESS: A PERSONAL VIEW FROM THE ANGEL VIANNA METHODOLOGY}

\begin{abstract}
Body awareness is the center of the work done at the Angel Vianna dance college. One way of understanding body awareness is based on element softhenervous system responsible for the feeling process, such as neuron sand sensitivity receptors. This report presents details about the function in gof the sense somesthetic or somatosensory, as well as its subdivisions proprioception, exteroception and interoception. It Will be discussed how these concepts are present during the learning of the Angel Vianna methodology from a personal perspective, based on the author's training period, between the years 2016 to 2020 . We have traditionally learn ed little about the sensitive dimension of the body, especially its deepest layers. That is why it is important that we can recognize the presence of bodily sensations: name and experience them through a conscious directi on of attention, contributing to a greater agency of movement choices, regulating degrees of effort and revealing new possibilities for action.
\end{abstract}

Keywords: Angel Vianna Methodology; Nervous System; Body Awareness.

\section{Introdução}

Em suma, meu corpo não é apenas um objeto entre todos os outros objetos, um complexo de qualidades entre outros, ele é um objeto sensível a todos os outros, que ressoa para todos os sons, vibra para todas as cores, e que fornece às palavras a sua significação primordial através da maneira pela qual ele as acolhe. (MERLEAU-PONTY, 2011, p. 317) 
A intenção inicial deste trabalho era reunir conceitos da área da neurociência que ajudassem na compreensão e embasamento de práticas de consciência corporal presentes na metodologia Angel Vianna, assim como os benefícios que esta metodologia é capaz de promover. No entanto, para preservar as regras do método científico tradicional, pautado na validação por comprovação e na impessoalidade, evitaria falar especificamente sobre vivências pessoais. Iniciada a pesquisa, porém, percebi que boa parte das reflexões e questionamentos estavam enraizados em tudo senti e experimentei ao longo da formação e seria impossível não ser pessoal.

Para os biólogos Humberto Maturana e Francisco Valera (2001), tudo que é dito é dito por alguém. Em A Árvore do Conhecimento os autores esmiúçam esta afirmação aparentemente simples, mas que tem impactos relevantes na forma como entendemos o processo de conhecer e, consequentemente, o processo de viver. Pesquisadores de muitas outras áreas defenderam que o campo da percepção é complexo demais para ser explicado por meio de abordagens reducionistas, a realidade que se apresenta para cada um é singular e representa uma construção pessoal em constante transformação.

Na faculdade de dança Angel Vianna, localizada no Rio de Janeiro, estudamos o papel do corpo nesta construção pessoal, em especial a influência do fluxo de informações somestésicas ou somatossensoriais, e como este estudo pode levar à ampliação do campo perceptivo como um todo. Segundo o professor José de Albuquerque Vieira (2008, p. 20), "enquanto o cientista busca a realidade, o artista trabalha com as possibilidades do real". Ao produzir um relato fruto de uma faculdade de arte, meu objetivo é refletir sobre outras dimensões do real, particularmente, a dimensão das sensações do corpo.

Meu ingresso na Angel Vianna se deu aos vinte e seis anos, sem nenhuma vivência anterior com dança. Formada em Administração, havia acumulado anos de sedentarismo e reconhecia meu corpo como um objeto, um mero instrumento à disposição. Nessa época, boa parte da minha noção de identidade era ocupada pelo pensamento e se alguém me pedisse para apontar um local específico onde o meu "eu" estava localizado, a resposta mais apropriada seria, sem dúvida, a cabeça. Na maior parte do tempo, este corpo se apresentava como um problema. Por fora, suas formas e texturas eram temas frequentes de insatisfação e por dentro, dores de todo tipo me acompanhavam e qualquer sensação física era suspeita, como se não devesse estar ali. 
Em 2014, conheci um tipo de meditação budista, chamada Vipassana. Ao aprender Vipassana participa-se de um curso de dez dias, onde só há uma atividade: sentar, fechar os olhos e perceber as sensações do corpo. A participação neste curso foi um ponto de partida importante e desde então pude perceber sensações que nunca havia notado antes, em especial as mais sutis como vibrações, pequenas pressões, leves formigamentos... Percebi também que as sensações não eram estáticas, que se modificavam o tempo todo, além da fantástica capacidade de se transformarem com o grau de atenção que recebiam.

A curiosidade sobre o corpo e suas possibilidades levaram-me, em 2016, à graduação em Dança na Faculdade Angel Vianna. É da experiência vivida na faculdade que surgiu o material e a motivação para escrever este trabalho, cuja pesquisa é também reflexo de minha participação em um dos núcleos de estudos da faculdade - Contribuições Multiprofissionais da Dança - coordenado pela professora Vanessa Matos, onde investiguei o papel da propriocepção no ensino-aprendizado da dança.

\section{Objetivos e metodologia da pesquisa}

A prática da consciência corporal pode ser entendida pela perspectiva da neurociência que tem como base o estudo do sistema nervoso. Assim como a dança evidencia na prática, este estudo reconhece o corpo como um campo sensível em todas suas camadas. O presente relato discutirá como conceitos a respeito da sensibilidade corporal estão presentes na metodologia Angel Vianna.

A discussão partirá de um olhar pessoal, baseado nos quatro anos de formação da Faculdade Angel Vianna (entre 2016 a 2020). Serão expostas algumas das práticas vividas em aula e reflexões sobre seus efeitos na experiência. A ideia é que esta reflexão pessoal contribua para o fortalecimento da compreensão do corpo em sua integridade e para o desenvolvimento desta compreensão por meio da consciência corporal.

O objetivo geral é relacionar o entendimento do corpo e do movimento a partir da metodologia Angel Vianna e do sistema nervoso. Os objetivos específicos são: identificar componentes do sistema nervoso envolvidos na sensibilidade corporal e refletir sobre experiências em aula associando-as ao sentido somestésico. 


\section{O corpo e sua qualidade sensível}

Condição de existência para todos os seres vivos é o movimento de se ajustar ao meio e manter o equilíbrio. Na biologia, esta característica é chamada de homeostase, "o equilíbrio é uma propriedade intrínseca e constitutiva da vida orgânica e mental" (PIAGET, 1967, p. 88). Este atributo requer que os organismos vivos reconheçam o meio em que vivem, identificando informações que sejam relevantes para própria estrutura e agindo de acordo com o que foi percebido.

Por exemplo, se está muito calor e um corpo se distancia da sua temperatura ideal de funcionamento, antes de acionar qualquer medida de resfriamento ele deve, primeiro, ser capaz de notar que houve uma mudança de temperatura. Segundo Keleman (2001, p. 52), "excitabilidade é o componente central do sistema nervoso, trata-se da capacidade que determinadas células tem em reconhecer estímulos que as atravessam”. A excitabilidade é uma característica fundamental na manutenção do equilíbrio dos processos do organismo. A todo momento somos atravessados por uma quantidade inimaginável de estímulos, mas a grande maioria é registrada de forma inconsciente, principalmente os estímulos originados no espaço interno da estrutura corporal.

Boa parte das orientações que ouvi em aula durante os quatro anos da graduação envolvia algo sobre "escutar o corpo", que, na prática, significa direcionar a atenção para a própria anatomia. Durante as aulas praticávamos identificar limites do corpo por meio das sensações na pele, intensidades de contração por meio das variações no tônus muscular e possibilidades de movimentos a partir dos pontos de articulação entre as estruturas ósseas. Éramos constantemente convidados a reconhecer a presença viva do esqueleto e sua arquitetura. Eu ouvia essas instruções com estranheza, já que minha noção de identidade nunca havia considerado a presença de ossos, muito menos de ossos vivos.

Lent (2010) afirma que a sensibilidade corporal é provavelmente a modalidade sensorial mais antiga entre os animais. Ainda assim, durante o longo processo de escolarização, onde aprendemos conteúdos ditos fundamentais, há pouquíssimo espaço para reflexão sobre as sensações do corpo. O que se observa é um ensino fortemente orientado para a abstração, que restringe a cognição à dimensão pensamento e da interpretação simbólica da realidade.

Culturalmente aprendemos sobre os cinco sentidos visão, audição, paladar, olfato e tato. Mas afinal, qual forma de sensibilidade é trabalhada na Faculdade Angel Vianna? 


\section{Neurônios e a linguagem do sistema nervoso}

Cada célula do corpo se especializa para exercer diferentes funções no organismo e uma importante célula especializada do sistema nervoso é o neurônio. É um tipo de célula que, ao ser estimulada, produz e veicula sinais proporcionais ao estímulo percebido, os chamados "potenciais de ação".

Os potenciais de ação são sinais pelo quais o sistema nervoso recebe, analisa e transmite a informação (KANDEL, 2014), funcionam como atos de "significação" do meio, onde os sinais elétricos gerados pelas células comunicam dados sobre os estímulos dos ambientes externo e interno. Lent esclarece que:

Uma linguagem funciona por meio de um código de representação. Os idiomas, por exemplo, são códigos de representação de ideias, que empregam letras como unidades, sendo elas agregadas em conjunto de palavras, estas em frases, frases em parágrafos e assim por diante (...). No caso dos neurônios, é a variação da frequência do disparo dos neurônios que lhes permite veicular, em código, diferentes mensagens. (LENT, 2010, p. 98)

Por exemplo, quando massageamos o pé com uma bolinha de tênis em uma aula de metodologia Angel Vianna, provocamos o surgimento de potenciais de ação em determinados neurônios responsáveis pela percepção da sola dos pés. Estes neurônios se comunicarão com outros neurônios por meio de sinais químicos e elétricos, as sinapses, e assim "seremos informados" da presença de um objeto em forma de esfera, revestido de feltro, com a maleabilidade de uma borracha e em contato com o corpo.

Nas sinapses as informações originalmente transmitidas poderão ser transformadas antes de seguir adiante e, segundo Machado (1991, p. 250), "até serem totalmente processadas as mensagens sensoriais sofrem uma série de modificações como ampliação, redistribuição, filtração, facilitação, inibição, etc.". Isso quer dizer que, da mesma forma que o conteúdo de uma conversa entre amigos passa pelos filtros do que cada um está falando, interpretando e ouvindo, os neurônios modificam as informações à medida que ela percorre os circuitos de comunicação. Esta forma de organização do sistema nervoso revela uma natureza criativa sobre a realidade onde as experiências dos sentidos não são representativas, mas resultado de interações dinâmicas e contínuas entre o organismo e o ambiente. 


\section{Receptores de sensibilidade}

No momento em que somos atravessados por uma energia do ambiente, seja ela do ambiente externo ou interno, ela será captada por neurônios sensitivos primários ou receptores de sensibilidade. São componentes que funcionam como as portas da percepção no sistema nervoso. Marçal (2019) afirma que os receptores de sensibilidade são responsáveis pela capacidade humana de se saber encarnado, presente em um corpo tangível, material. Eles identificam a intensidade e duração de um estímulo e são as estruturas sensíveis que primeiro produzem as informações sensoriais que fluirão pelas redes de neurônios.

Espalhados por todo o organismo, os receptores de sensibilidade podem ser encontrados nos olhos, ouvidos, língua, pele, nos músculos, ossos, vísceras... Como apresentam uma grande variedade funcional e morfológica são agrupados em categorias que levam em consideração o tipo de energia que são capazes de captar:

- Mecanorreceptores captam estímulos mecânicos;

- Quimiorreceptores captam estímulos químicos;

- Fotorreceptores captam estímulos luminosos;

- Termorreceptores captam variação de temperatura.

Além de serem específicos para tipos de energia, os receptores também são específicos para limiares desta energia (KANDEL, 2014). Por exemplo, na visão há receptores específicos para determinadas cores, no paladar há receptores para diferentes sabores e o mesmo acontece para as sensações corporais: um leve toque na pele é percebido por receptores diferentes daqueles que notam um beliscão. Identificar e reconhecer esta variedade perceptiva faz parte da prática da consciência corporal que se direciona para os produtos da interação entre corpo e ambiente, ou seja, com diferentes tipos e intensidades de sensações.

As informações captadas pelos receptores de sensibilidade irão compor as famosas modalidades sensoriais. Segundo Lent (2010), a função primordial das modalidades sensoriais é realizar a tradução da informação contida nos estímulos ambientais para a linguagem do sistema nervoso. Assim a visão é resultado da estimulação dos fotorreceptores, já o paladar e o olfato baseiam-se em sinais dos quimiorreceptores. $\mathrm{O}$ sentido somestésico ou somatossensorial é o mais variado de todos. Compreende a tradução de quimiorreceptores, termorreceptores e mecanorreceptores que, ao contrário dos demais sentidos, não se encontram concentrados em uma parte do corpo, mas espalhados por todo ele. 
Os receptores de sensibilidade do sentido somestésico tem participação fundamental nas aulas de metodologia Angel Vianna e por isso é importante conhecer suas particularidades. O quadro 1 resume os receptores sensoriais somestésicos que já foram identificados, o tipo de energia que captam, sua localização no corpo e a função que exercem.

Quadro 1 - Receptores sensoriais

\begin{tabular}{|c|c|c|c|}
\hline Tipo morfológico & Energia & Localização & Função \\
\hline 1. Terminações livres & $\begin{array}{c}\text { Mecânica, térmica, } \\
\text { química }\end{array}$ & $\begin{array}{c}\text { Derme, epiderme, } \\
\text { órgãos internos, vasos } \\
\text { sanguíneos, articulações }\end{array}$ & $\begin{array}{l}\text { Dor, temperatura, } \\
\text { tato grosseiro, } \\
\text { propriocepção }\end{array}$ \\
\hline $\begin{array}{l}\text { 2.Corpúsculos de } \\
\text { Meissner }\end{array}$ & Mecânica & Epiderme & $\begin{array}{l}\text { Tato, pressão } \\
\text { vibratória }\end{array}$ \\
\hline 3. Corpúsculo de Pacini & Mecânica & $\begin{array}{l}\text { Derme, periósteo, } \\
\text { parede das vísceras }\end{array}$ & $\begin{array}{l}\text { Pressão } \\
\text { vibratória }\end{array}$ \\
\hline 4. Corpúsculo de Ruffini & Mecânica & $\begin{array}{c}\text { Derme, ligamentos e } \\
\text { tendões }\end{array}$ & $\begin{array}{l}\text { Estiramento da } \\
\text { pele }\end{array}$ \\
\hline 5. Discos de Merkel & Mecânica, térmica & Epiderme & $\begin{array}{c}\text { Tato, pressão } \\
\text { estática }\end{array}$ \\
\hline 6. Bulbos de Krause & Mecânica & $\begin{array}{c}\text { Bordas da pele com } \\
\text { mucosas }\end{array}$ & Função incerta \\
\hline 5. Folículos pilosos & Mecânica & Pele & Tato \\
\hline $\begin{array}{l}\text { 6. Órgãos tendinosos de } \\
\text { Golgi }\end{array}$ & Mecânica & Tendões & Propriocepção \\
\hline 7. Fusos musculares & Mecânica & Músculos esqueléticos & Propriocepção \\
\hline
\end{tabular}

Fonte: Adaptado de Lent (2010, p. 200).

Terminações livres, Corpúsculos de Meissner, de Pacini, de Ruffini, Discos de Merkel, Bulbos de Krause, Folículos pilosos, Órgãos tendinosos de Golgi e Fusos musculares: assim como radares, estes receptores têm um campo de atuação mais ou menos definido, ou seja, um alcance de estimulação até onde são capazes de detectar um estímulo. Deve-se ressaltar que, apesar de apresentarem um padrão, estas estruturas não são estáticas e podem 
expandir-se, contrair-se ou deslocar-se em função de variadas influências como atenção, estresse, cansaço etc. (LENT, 2010).

(...) Embora a consciência não registre tudo, o sistema nervoso recebe e processa continuamente todas as informações sobre a posição e o movimento das partes do corpo como um todo, sobre o estado de nossas vísceras, sobre a textura, a forma e a temperatura dos objetos que tocamos e sobre a integridade de nossos tecidos. Essas informações são selecionadas, filtradas e encaminhadas a diferentes regiões neurais, que as vão utilizar de diversas maneiras. (LENT, 2010, p. 229)

Se fecharmos os olhos por um instante e focalizarmos nossa atenção no corpo poderemos perceber que ele é inundado por sensações de todo tipo. Mas a verdade é que durante boa parte de nossa vida, estas sensações corporais são captadas inconscientemente e não chegam à percepção. Nas práticas em aula há exercícios específicos para a estimulação dos diferentes receptores somestésicos a fim de torná-los contribuir para o registro consciente das informações. Com isso, espera-se que o campo perceptivo de alunas e alunos seja potencializado, acionando uma escuta ampliada do corpo.

\section{O sentido somestésico (ou somatossensorial)}

O processamento das informações originadas nos receptores de sensibilidade manifesta-se na experiência por meio dos sentidos. Este processamento envolve o agrupamento das informações dos receptores em locais específicos do cérebro, o que resulta na classificação básica popularmente conhecida: visão, audição, olfato, paladar e tato. No entanto, como dito antes, essa é uma concepção limitada da capacidade perceptiva humana, principalmente porque exclui boa parte das informações captadas pelos receptores de sensibilidade corporal, localizados em tecidos profundos do organismo.

As informações enviadas pelos receptores de sensibilidade corporal compõem o que neurocientistas chamam de sentido somestésico, somatossensorial ou somato-sensitivo e são palavras sinônimas que carregam o mesmo prefixo, "soma", do latim, corpo. O sistema somestésico envolve a combinação outros subsistemas em que cada um transmite ao cérebro sinais particulares sobre o estado do corpo. Neste trabalho será usada a classificação do neurofisiologista Charles Sherrigton (1857-1952), que dividiu o sentido somestésico em três 
categorias, usando como critério o local de origem do estímulo. Sob esta lógica a somestesia divide-se em exterocepção, propriocepção e interocepção.

A primeira categoria, exterocepção, compreende estímulos externos, vindos fora da estrutura corporal e captados pelo maior órgão do corpo: a pele. A pele, que recobre toda a superfície corporal, é o órgão do tato e permite sensações de contato, pressão e vibração além de sensações térmicas e de dor (KANDEL, 2014). Dentre os três subsistemas somestésicos o tato é provavelmente o mais conhecido.

O sistema interoceptivo compreende estímulos internos, aqueles associados ao funcionamento das vísceras. Segundo Damásio (2013), este sentido reconhece mudanças no meio químico das células gerando sensações que nos informam sobre estados elementares do organismo como por exemplo, a fome e a sede. Na literatura a interocepção é também associada a aspectos emocionais, conferindo uma noção geral de bem ou mal-estar.

Por último o sistema proprioceptivo que, assim como a interocepção, compreende estímulos originados no interior da estrutura corporal. Apesar de pouco falada, a propriocepção é um sentido fundamental para manutenção da postura e formação do movimento e por isso também é denominada de cinestesia por alguns autores. Este sentido é a capacidade de percebermos nossa geometria corporal, fornecendo informações sobre tamanho e relação entre ossos, articulações e, principalmente, o tônus muscular. Como os músculos atuam de forma permanente sobre o esqueleto, as sensações relativas ao tônus muscular também são contínuas. Por isso, a propriocepção tem papel importante na construção da identidade do indivíduo. O neurologista Oliver Sacks (1997, p. 64) ao relatar o caso grave de uma paciente que perdeu toda a sensibilidade proprioceptiva escreveu: "Ela ainda sente, que seu corpo está morto, que ele não é real, que não é dela - ela não pode apropriar-se dele”. É a propriocepção que fornece ao sistema nervoso a percepção mais tangível do corpo.

Assim, durante uma aula, podemos explorar a riqueza do sistema somestésico e suas subdivisões ao notar as contrações dos músculos das pernas e do tronco que se tencionam para manter a postura ereta. Podemos experimentar também a expansão e o retraimento da caixa torácica durante a respiração, as batidas do coração, o fluxo de sangue, a temperatura do corpo, o toque da roupa na pele... E desta forma, o sistema nervoso torna-se consciente das percepções por ele próprio geradas, criando um ambiente que parece favorecer o processamento das informações dos receptores de sensibilidade pelo sistema nervoso central.

Da periferia do corpo, os estímulos sensoriais seguirão para o sistema nervoso em direção ao córtex somatossensorial, onde neurônios se agrupam em uma ordem específica e 


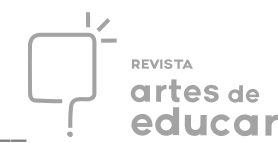

formam mapas no cérebro. São locais para onde se destinam as informações de cada parte do corpo. Voltando ao exemplo de aula e o exercício da bolinha de tênis que massageia o pé, estes, os mapas permitem responder a perguntas como: qual a relação entre o tamanho do pé e as outras partes corpo? Que parte do corpo está em contato com a bolinha? Para onde é possível deslocar a bolinha pela superfície da sola do pé?

Chamados de mapas somatotópicos, estas pequenas áreas de tecido nervoso revelam relações funcionais entre as partes do corpo, o grau detalhamento sensorial que necessitamos para cada uma. Isso porque quanto maior a área de representação de uma região no mapa, maior a sua capacidade de processamento (MACHADO, 1991). Uma representação interessante de um desses mapas é o homúnculo sensorial, proposto por Wilder Penfield (1917-1969), que reúne as informações táteis da superfície corporal.

Figura 1 - Escultura do homúnculo sensorial

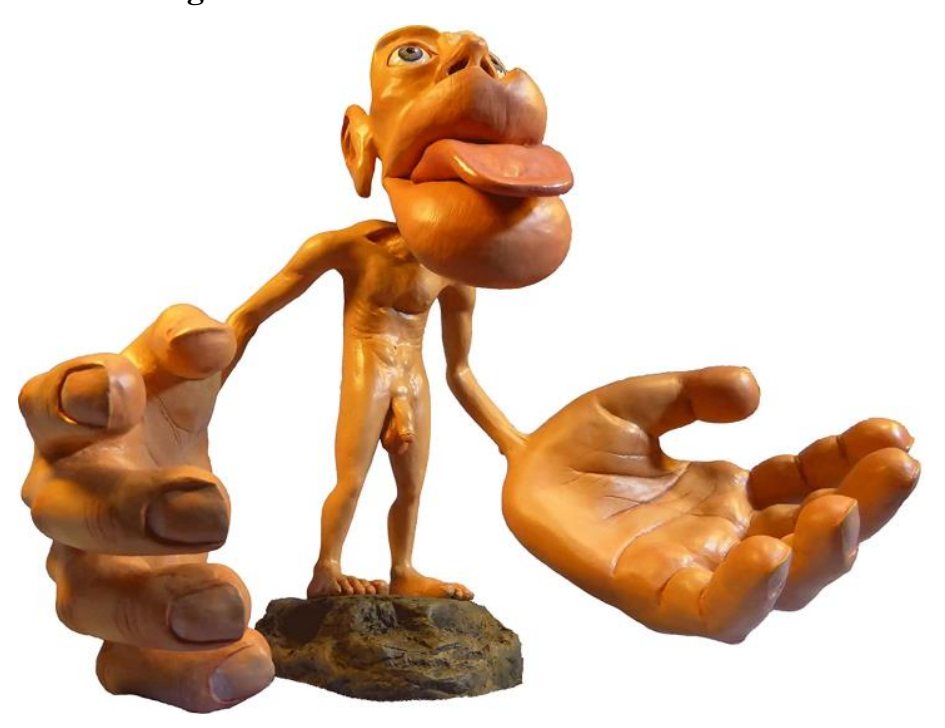

Fonte: Museu de História Natural de Londres, Reino Unido.

A figura 1 é uma escultura que simula as proporções de cada área do corpo no mapa somatotópico do córtex. Na imagem é possível notar que determinadas áreas apresentam definição sensorial muito mais acentuada do que outras, como as mãos, os lábios e a língua. É importante ressaltar que, assim como todo o sistema nervoso, os mapas somatotópicos também estão sujeitos à plasticidade e podem modificar-se de acordo com a aprendizagem e outras condições ambientais (LENT, 2010). As qualidades perceptivas de diferentes partes do corpo podem ser trabalhadas em aula de forma a tornar os alunos mais conscientes de seus próprios mapas. 


\section{Metodologia Angel Vianna e a experiência do sentido somestésico}

Ao contrário de outros sentidos que podem ser atenuados de acordo com a situação, o sentido somestésico está sempre presente. Podemos fechar os olhos, tapar os ouvidos, o nariz... mas o corpo nunca! Calores, contatos, coceiras, tensões, arrepios, vibrações, pressão, contração, alongamento, dor, fome e sede são apenas alguns exemplos de sensações que se misturam e se alternam em nossa consciência, desde o nascimento até a morte. O corpo é o lugar que estamos sempre habitando, nossa estrutura primordial.

Mas o sentido somestésico é um tópico pouco comentado em nossa educação, assumese que ele não precisa ser explorado, é inato, está dado. Assim, ao longo do amadurecimento humano, pouco se reflete sobre a presença das sensações corporais e a maior parte das informações exteroceptivas, interoceptivas e proprioceptivas captadas acabam sendo registradas inconscientemente. Como resultado, predominam no movimento respostas motoras automatizadas levando à limitação da ação de músculos e articulações. Os efeitos desta imobilização, no entanto, vão além da biomecânica podendo ser sentidos como um todo pelo indivíduo.

Na contramão deste cenário, durante uma aula de metodologia Angel Vianna, atuamos sobre nossa representação somestésica, trazendo a atenção para as informações dos receptores de sensibilidade e promovendo plasticidade do sistema nervoso. Sua compreensão de corpo é fruto de uma pesquisa multidisciplinar cuja maturação está inseparável de sua história de vida.

Angel Vianna nasceu em 1928 em Minas Gerais e, desde cedo, a expressão artística foi relevante em sua personalidade. Estudou piano, desenho, pintura e escultura e, aos 20 anos, entrou para o Ballet de Minas Gerais, onde iniciou sua história com a dança. $\mathrm{O}$ aprendizado do balé abriu espaço para uma curiosidade crescente sobre o corpo e levou Angel a investigar a lógica por trás dos movimentos e passos que realizava ao dançar. Segundo ela, era preciso entender como funcionava o corpo para poder utilizá-lo. Com o aprofundamento de estudos de anatomia, percebeu que poderia influenciar movimentos a partir da percepção atenta dos tecidos corporais e suas particularidades.

Durante seus estudos, Angel tomou conhecimento de outros profissionais que seguiam uma linha de pensamento parecida, unindo mente e corpo. Resende (2008) afirma que, a fim de construir um corpo mais expressivo, o método Angel Vianna apropriou-se de abordagens de educação somática. Dentre estas abordagens, destaca-se a Eutonia, de Gerda Alexander (1908-1994). 


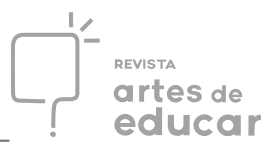

Atualmente com 93 anos, Angel segue trabalhando e acumula uma longa carreira de dedicação à pesquisa corporal. Seus desdobramentos incluem áreas de conhecimentos de diversas áreas, como arte, pedagogia, psicologia, biologia, entre outros.

O que podemos observar é que sua metodologia resulta de um pensamento muito amplo, que reconhece e a complexidade da natureza humana e procura explorá-la por meio do movimento e da consciência. Angel aponta que a dança é para todos aqueles que estejam interessados em aprender e seu trabalho vem sendo aplicado em pessoas dos mais variados perfis: bailarinos, pessoas sem experiência, pessoas com deficiência, crianças, adolescentes, idosos.

As aulas são um convite à escuta de si, à afinação do sistema nervoso com o momento presente. Para que o trabalho seja eficaz, portanto, é necessário que alunas e alunos abandonem o padrão cultural de se mover no automático e dediquem-se a decifrar as informações conforme se apresentam à consciência. Caetano (2017) enfatiza que a realização dos procedimentos somáticos em torno da propriocepção, exterocepção e interocepção são realizados por meio de um foco interno, numa atitude receptiva aos estímulos. Com a prática, percebemos que essas informações sempre estiveram disponíveis, mas nunca haviam sido notadas.

Um dos primeiros exercícios que aprendemos é simplesmente deitar no chão e notar os apoios, identificando pressões e contatos. Trata-se de um exercício de reconhecimento que depende do tato e da propriocepção. No entanto, o que percebemos quando tentamos executar esta simples tarefa é que muitos músculos se recusam a relaxar. Algumas partes do corpo doem, outras "repuxam", outras parecem, literalmente, "voar" enquanto deveriam estar relaxadas no chão. Ainda mais intrigante é quando nos damos conta de que a percepção do corpo não é uniforme, alguns lugares são facilmente percebidos enquanto outros parecem estar anestesiados.

A percepção que cada um tem de si é singular e tem relação, entre outros, com os mapas de representação somatotópica no cérebro, os quais são diretamente afetados pelo uso (ou falta de uso) que fazemos do corpo. Quando se começa a praticar, a identificação dos tecidos é difícil e ossos, músculos e articulações podem parecer um bolo de sensações aleatórias. Mas, com a prática, as sensações vão ficando mais distinguíveis e, assim como um chefe de cozinha desenvolve o paladar para distinguir sabores e temperos, as práticas de consciência corporal desenvolvem a somestesia para que possamos diferenciar posturas e movimentos.Contudo, despertar o sentido somestésico e torná-lo mais apurado não é uma 
tarefa fácil, requer paciência e dedicação. Para facilitar este processo, ao longo do aprendizado, usamos pistas que servem para convocar a atenção do sistema nervoso.

A qualquer dado momento, os indivíduos estão conscientes de apenas de uma pequena fração dos estímulos sensoriais que os atingem. À medida que olha o mundo, o indivíduo foca a atenção nos objetos ou cenas específicos que têm especial interesse e exclui os outros (KANDEL, 2014, p. 342).

É comum fazermos uso de objetos como bolinhas de tênis, bambus, bastões, tecidos ou, então, as próprias mãos. Eles funcionam como uma ponte para a experiência somática, ativando os receptores de sensibilidade e potencializando a compreensão do corpo por meio da experiência do contato. Por exemplo, para estimular diferentes receptores táteis usamos toques leves, fortes, contínuos ou intermitentes, procuramos identificar, linhas, curvas e proeminências que ajudem a informar sobre perímetros e volumes corporal. Também usamos o toque para criar zonas de calor e estimular a percepção térmica. Estes exercícios são essenciais na alimentação dos mecanismos que contribuem para a atualização dos mapas somatotópicos do córtex somatossensorial.

Outra forma de desenvolver a somestesia é por meio da propriocepção. Os exercícios de propriocepção feitos na faculdade nos ensinam que há infinitas formas de executar um mesmo movimento e que somos capazes de investigar circuitos diferentes daqueles que estamos acostumados. A prática envolve criar circunstâncias para que o corpo descubra essas novas possibilidades de movimento, como por exemplo, pesquisando as diferentes partes do corpo que podemos apoiar no chão. De acordo com Teixeira (2008), este sentido é estimulado pelo trabalho das articulações, com exercícios direcionados para despertar a percepção das localizações espaciais e modulação de tensões musculares. O estudo sensorial das tensões musculares ajuda na melhor distribuição de forças, contribuindo também para a prevenção de quedas e lesões.

\section{Conclusão}

A fundamentação para práticas da metodologia Angel Vianna pode ser encontrada em conceitos básicos da neurociência, que descrevem os componentes biológicos por trás do sistema sensorial. Tradicionalmente aprende-se pouco sobre a dimensão sensível do corpo, principalmente de suas camadas mais profundas. Por isso é importante que possamos Revista Interinstitucional Artes de Educar. Rio de Janeiro, V. 7, N. 1 - pág. 556-570 janeiroabril de 2021: "Pedagogias Vitais: Corpo, Desejo e Educação" DOI: 10.12957/riae.2021.53562 
reconhecer a presença das sensações corporais: nomeá-las e vivenciá-las por meio de um direcionamento consciente da atenção.

Ao trazemos consciência para as sensações corporais atuamos intencionalmente sobre a capacidade plástica do sistema nervoso, promovendo a funcionalidade de campos receptores, modificando a percepção que temos de nós mesmos. Com o tempo, pude compreender que habitar o corpo, como Angel propõe, é uma habilidade que pode (e deve) ser desenvolvida, assim como acontece com a habilidade de ler e escrever. Resultando em uma maior agência das escolhas de movimento, regulando graus de esforço e revelando novas possibilidades de ação.

\section{REFERENCIAS}

BATSON, G. Update onProprioception: Considerations for Dance Education. JournalofDanceMedicine\& Science, v. 13, n. 2, p. 35-41, 2009.

CAETANO, P. Pistas somáticas para um estudo da corporeidade: uma aprendizagem das sensações. Fractal, v. 29, n. 2, p. 168-176, 2017.

DAMÁSIO, A. E o cérebro criou o homem. São Paulo: Cia das Letras, 2013.

KELEMAN, S. Anatomia Emocional. São Paulo: Summus, 1992.

KANDEL, E. et al. Princípios de neurociências. Porto Alegre: AMGH, 2014.

LENT, L. Cem Bilhões de Neurônios? Conceitos Fundamentais de Neurociência. São Paulo: Atheneu, 2010.

MARÇAL, M. B. Estudo da Propriocepção - aplicado à formação do professor em artes. Curitiba: Editores CRV, 2019.

MACHADO, A. Neuroanatomia Funcional. Rio de Janeiro/São Paulo: Atheneu, 1991.

MATOS, V. Anatomopoesia - uma proposta pedagógica de integração dos saberes.Revista Interinstitucional Artes de Educar, Rio de Janeiro, v. 5, n.3, p. 695-725, 2019.

MATURANA, H.; VARELA, F. A Árvore Do Conhecimento: As bases biológicas do entendimento humano. São Paulo: Palas Athena, 2001.

PIAGET, J. Seis estudos de psicologia. Rio de Janeiro: Forense Universitária,1999.

MERLEAU-PONTY, M. Fenomenologia da Percepção. São Paulo: WMF Martins Fontes, 2011. 
RESENDE, C. Saúde e corpo em movimento: Contribuições para uma formalização teórica e prática do método Angel Vianna de Conscientização do Movimento como um instrumento terapêutico. Dissertação de Mestrado em Saúde Coletiva, Universidade Federal do Rio de Janeiro, 2008.

SACKS, O. O homem que confundiu sua mulher com um chapéu e outras histórias clínicas. Rio de Janeiro: Companhia das Letras, 1997.

TEIXEIRA, L. Inscrito em meu corpo: uma abordagem reflexiva do trabalho corporal proposto por Angel Vianna. Dissertação de mestrado em Teoria e Técnicas Teatrais, Universidade Federal do Estado do Rio de Janeiro, 2008.

VIEIRA, J. A. Teoria do Conhecimento e Arte: formas de conhecimento - arte e ciência uma visão a partir da complexidade. Fortaleza: Expressão Gráfica e Editora, 2008.

\footnotetext{
i Bacharel em Administração de Empresas - Faculdade de Administração e Ciências Contábeis, Universidade Federal do Rio de Janeiro (UFRJ). Licencianda em Dança - Faculdade Angel Vianna - desde 2016. Nesta faculdade, integrante do Núcleo de Estudos e Pesquisas Contemporâneas do Corpo: Contribuições

Multiprofissionais da Dança - desde 2019. Bacharelanda em Fisioterapia - Escola de Ciências da Saúde, Instituto Brasileiro de Medicina e Reabilitação (IBMR) - desde 2020. Instituição/Afiliação Faculdade Angel Vianna. Rio de Janeiro / Brasil. ORCID iD https://orcid.org/0000-0001-6715-204X.
} 